\title{
METODOLOGIA DE NEGOCIAÇÃO ENTRE \\ UNIVERSIDADE-EMPRESA-GOVERNO: UMA ALAVANCA PARA O PROCESSO DE INOVAÇÃO TECNOLÓGICA
}

\author{
NEGOTIATION METHODOLOGY AMONG \\ UNIVERSITY-COMPANY-GOVERNMENT: \\ A VECTOR FOR THE TECHNOLOGICAL INNOVATION PROCESS
}

\author{
Eloiza Aparecida Silva Ávila de Matos ${ }^{1}$; João Luiz Kovaleski \\ ${ }^{1}$ CEFET-PR/Unidade Ponta Grossa, elomatos@onda.com.br \\ ${ }^{2}$ CEFET-PR/Unidade Ponta Grossa, kovaleski@ pg.cefetpr.br
}

Recebido para publicação em: 29/11/2004

Aceito para publicação em: 15/02/2005

\section{RESUMO}

A busca de formas, meios e estratégias apoiadas e estimuladas por políticas de governo que permitam o desenvolvimento favorável de um entorno para a inovação tecnológica, constituído por todos os segmentos sociais, tornam estreitas as atividades de cooperação entre as Universidades $e$ as Empresas de forma que esses parceiros se complementem e promovam maior capacitação tecnológica e desenvolvimento econômico. O sucesso dessas parcerias, pautado sob o caminho das negociações, depende da gestão eficiente das interfaces - desde o alinhamento de percepções dos cooperantes a respeito de quais são os diferentes objetivos visados, à relação e os condicionantes que cada cultura impõe, até o gerenciamento dos projetos e atividades envolvidas na transformação dos objetivos estipulados em resultados tangíveis. A existência de um encaminhamento metodológico para negociação entre universidade-empresa-governo contribui para o aprimoramento e ampliação das relações com parceiros e facilita a transferência de tecnologia das universidades para as empresas, constituindo-se importante vetor para o processo de inovação tecnológica. Dessa forma, o objetivo principal deste trabalho é apresentar uma proposta de metodologia de negociação entre universidade-empresa-governo considerando a necessária resposta qualitativa à questão: como conduzir o processo de negociação na relação universidade-empresa-governo em transferência de tecnologia? Portanto, a natureza básica do estudo em questão é caracterizada como exploratória, tendo em vista que buscamos maior compreensão a respeito do problema da interação universidade-empresa-governo e a identificação dos processos de negociação.

Palavras-chave: Negociação, inovação, relação u-e-g

\section{Universidade e empresa e governo: um processo dialógico}

Podemos tentar entender genericamente as esferas em que se projetam - de um lado a universidade com sua cultura individualizada e disciplinar, cujo trabalho de pesquisa efetiva-se em longo prazo e o resultado visa à maximização de conhecimentos com irrestrita e ampla divulgação, 
os trabalhos são expostos de forma permanente à comunidade — por outro lado, para a empresa as pesquisas são oportunidades ímpares de conhecimentos avançados de gestão e tecnologias inovadoras, os resultados centram-se, portanto, na obtenção de produtos e processos com eficiência, qualidade e velocidade. Restringindo-os a seus proprietários, quase sempre protegidos pelas regulamentações de propriedade intelectual e industrial. A empresa é seletiva quanto à utilização da informação.

A universidade tem como prioridade o investimento em geração de conhecimento e a expectativa de que a tecnologia promova o desenvolvimento da sociedade em geral; a empresa por sua vez volta sua atenção para a produtividade, competitividade, sobre os lucros, sem os quais não conseguiria sobreviver e, por conseguinte não cumpriria sua função social que é gerar empregos atendendo às necessidades mais específicas. Fracasso (1990) citado por Nascimento (1999, p. 60) aponta que a tecnologia, para a indústria, é um instrumento para sua participação no mercado. Reconhecemos, assim, um ponto crítico, embora ambas se completem em relação à esfera social, os objetivos divergem em curto prazo.Alguns pontos conflitantes precisam ser administrados de forma coerente e madura, como comenta Reis (2000, p. 124), “Acreditamos que para estabelecer uma verdadeira parceria entre a universidade e a empresa se faz necessário suplantar determinadas fases, as quais denominamos” degraus da parceria “. Estas seriam as fases de conhecimento, de confiança e de consolidação".

Atualmente o que ocorre é a mudança de uma interação bipolar entre universidade e empresa para uma interação multipolar, na qual autoridades governamentais de diversos níveis internacional, nacional, regional — e o setor produtivo são atores significantes e interagem no processo de inovação gerado por essas relações. Assim, as universidades vêm realizando atividades próprias das indústrias, através da formação de firmas spin-off e as empresas estão produzindo conhecimento e realizando treinamento dentro de formatos acadêmicos, com o auxílio das universidades.

Entre outras coisas, isto requer melhores níveis de educação para os novos postos de trabalho que vêm surgindo a cada momento, de forma que as populações possam participar da economia.

Verifica-se, nesse contexto, a utilização de modelos institucionais inovadores, com a formação de redes ou de consórcios em que participam duas ou mais organizações, de natureza similar ou distinta. Nesses consórcios existem interesses comuns dos participantes, para a execução de um determinado projeto e as motivações podem ser diferentes, uma vez que cada uma das instituições envolvidas tem seus próprios objetivos. O que cada organização busca é superar suas limitações, aumentando sua flexibilidade e sua capacidade de progredir. 
É nesse quadro que surge o novo modelo das relações universidade-empresa-governo em que se incluem desde as interações tênues e pouco comprometedoras, como oferecer práticas profissionais, até vínculos institucionais mais intensos, como é o caso de grandes programas de pesquisa cooperativa, que possibilitam repartir os créditos resultantes da comercialização dos resultados.

Entendemos, desse modo, que o processo de cooperação depende de dois fatores básicos: a busca da compatibilidade com o universo econômico, cultural e político das instituições e a existência de mediações eficientes.

Em decorrência, lançar mão de instrumentos de negociação no âmbito das universidades para promover a gestão coerente e eficaz das interfaces responsáveis pela dinamização e prospecção do "negócio tecnológico", introduz um novo conceito além daquele considerado como simples estruturas burocráticas da cooperação.

O grau de cooperação e estabilidade resulta então das faixas de interesses dos participantes.
[...] o modelo estratégico de ação pode se satisfazer com a descrição de estruturas do agir
imediatamente orientado para o sucesso, ao passo que o modelo do agir orientado para o
entendimento mútuo tem que especificar condições para um acordo alcançado
comunicativamente. Habermas (1989 p. 164 165)

Através de métodos e técnicas de negociação, depois de constatadas as divergências, os interlocutores poderão se ater às esferas de convergência, ampliando-as e reduzindo as diferenças, para tanto é preciso analisar os fenômenos sob novas óticas. As atitudes transparentes tendem a ampliar o grau de confiança, contribuindo, assim, para o entendimento. "O negociador, orientado para o sucesso das relações universidade-empresa negocia com o interlocutor a partir de uma metodologia baseada em procedimentos e em critérios legítimos e objetivos".(ÁVILA DE MATOS \& KOVALESKI, 2000, p. 59).

\section{O processo de negociação entre universidade-empresa-governo: um caminho a ser construído}

A negociação tem sido tratada como um assunto antigo, comum na vida das pessoas, porém sem um embasamento conceitual que garanta um bom desenvolvimento; ou ainda como um assunto de grande valia na atividade das pessoas de um modo geral, em especial, no mundo empresarial, que necessitaria de maior análise e sistematização das atividades.

Inicialmente, alguns estudiosos apresentaram-na como uma relação ganha-perde, ou seja, para um lado ganhar, necessariamente, outro terá que perder. Com o tempo percebeu-se que essa não possibilitava a continuidade de relacionamento futuro, uma vez que, uma das partes se considerava lesada. Mais recentemente, buscando-se atender as partes envolvidas e um relacionamento que possa ser duradouro tende -se para uma negociação classificada como ganha- 
ganha. Sob essa visão, ter ambos os lados satisfeitos e com suas necessidades básicas supridas; tornou-se princípio fundamental em negociação.

Desse modo, a manutenção das relações mais duradouras pode depender da utilização de uma estratégia que contemple os interesses das partes envolvidas.

Encontramos na literatura várias definições sobre o tema, abrangendo diferentes aspectos e enfoques. Procuramos reuni-las, observando aspectos conceituais semelhantes. "Negociação é um processo de comunicação bilateral, com o objetivo de se chegar a uma decisão conjunta". (FISCHER \& URY, 1985, p. 30)

Para tanto é necessário um conjunto de pessoas, com preparação intelectual, informações e interesse em debater todas as alternativas possíveis até constituir um plano de ação consensualizado. "Negociação é o processo de comunicação, com o propósito de atingir um acordo agradável sobre diferentes idéias e necessidades". (ACUFF, 1993, p.21).

A construção de um espaço voltado para a coordenação comunicativa das ações em que estejam presentes as condições necessárias para alcançar comunicativamente um acordo depende inicialmente da possibilidade interação entre os atores.

Portanto, a negociação envolve alguns conceitos extremamente significativos como processo, consenso e sinergia, pois "negociação importa em acordo e, assim, pressupõe a existência de afinidades, uma base de interesses que aproxime e leve as pessoas a conversarem".(MATOS, 1989, p. 240)

Entendemos, a partir de Matos, que sem a conversação não se pode negociar, e esta, não se improvisa, nasce de habilidades básicas, tais como: saber ouvir, trocar informações, opiniões, experiências; saber se posicionar, seduzir, persuadir, porque "uma negociação é um processo de comunicação interativo que pode ocorrer quando queremos algo de outra pessoa ou quando outra pessoa quer algo de nós”. (SHELL, 2001, p. 135)

A partir dessa premissa, a negociação é a interação que ocorre entre as partes até o acordo, este processo inclui comunicação, seleção e implementação de estratégias e táticas. As definições arroladas trazem em seu bojo os princípios fundamentais como a satisfação de necessidades, busca de interesses comuns e acordo, concorrendo para isso, a importância da comunicação.

Em outro posicionamento, mas num viés inserido na perspectiva da comunicação, a informação é parte fundamental e pode influenciar decisivamente na direção seguida pela negociação. A informação e o poder serão utilizados individualmente ou simultaneamente dependendo do processo ou ainda das pessoas envolvidas, dessa forma "negociação é o uso da informação e do poder, com fim de influenciar o comportamento dentro de uma rede de tensão". (COHEN, 1980, p.14) 
A negociação é um processo, portanto com etapas distintas e que requerem condutas básicas para determinar a forma como o negociador usa recursos, conhecimentos e habilidades. A maneira como se desenvolve este processo é decisivo para o desfecho da negociação. (POLLAN \& LEVINE, 1994, p. 6) afirmam que negociação é, depois de ler e escrever, a habilidade mais importante e necessária para alguém se tornar bem-sucedido pessoalmente, financeiramente e nos negócios. Assim, em se tratando de um processo de negociação entre universidade e empresa para transferência de tecnologia, é necessário que o negociador ou a equipe de negociadores formulem com propriedade os objetivos a serem alcançados tendo em vista a satisfação de ambos os lados e a busca do relacionamento duradouro, o ponto de partida é, sem dúvida, a identificação das necessidades, oportunidades e interesses.

Este pensamento é corroborado por Reis (2000 p. 133):

O segredo, a nosso ver, é conhecer a necessidade para, em consequiência, se disponibilizar o serviço. Justamente sobre este aspecto é que está a novidade, pois os processos de interação universidade-empresa até hoje desencadeados pela universidade, têm-se baseado na disponibilização de serviços sem ter o conhecimento da real necessidade do cliente. Por este motivo, com resultados nem sempre satisfatórios.

\section{Proposta de metodologia de negociação para transferência de tecnologia entre universidade-empresa e governo}

A proposta de metodologia de negociação, que passamos a apresentar, é de base conceitual com as seguintes premissas: trabalhar a partir da demanda tecnológica; buscar e manter alianças estratégicas; minimizar riscos.

Esta proposição se insere no contexto da negociação ganha-ganha em que surgem os acordos de parcerias, com foco em relacionamentos de longo prazo. Assim, consideramos que, na interação universidade-empresa, os acordos de parceria devem ser baseados nos verdadeiros interesses de longo prazo dos participantes.

Sua origem conceitual agrega a abordagem sistêmica e permite uma análise integrativa da negociação. Compomos a estrutura metodológica organizando-a por subsistemas integrados e interrelacionados com o objetivo de alcançar melhores patamares de resultados tendo em vista o enfoque principal: o processo de negociação.

Os acordos de parceria exigem alguns ajustes no processo de negociação e são essenciais à medida que o ambiente e os interesses são mutantes.

Devido a amplitude do campo de negociação entre Universidade e Empresa, nossa proposta não se restringe à capacitação de pessoal em técnicas de negociação utilizadas por 
negociadores quando sentam à mesa para as rodadas de negociação. Ela prevê um caminho que estabeleça a formação de alianças estratégicas originada em fontes de informação e conhecimento.

Por se tratar de objetos de negociação onde o material em discussão é a tecnologia, apontada anteriormente como um bem intangível do ponto de vista do conhecimento contido em cada produto ou serviço e trazer em seu bojo aspectos de extrema especificidade, focamos uma estrutura física e intelectual para o desenvolvimento de negociação para transferência de tecnologia da universidade para empresa, ao que denominamos de entorno para negociação.

O "entorno" é um sistema formado de subsistemas em interação dinâmica e tem a função de retroalimentação. As etapas metodológicas são ações desencadeadas dentro do sistema e dependem das interações com seu meio ambiente.

\section{1 - O entorno para negociação eficaz entre universidade-empresa}

Torna-se cada vez mais imprescindível que as universidades estruturem ambientes para negociação, para tanto consideramos alguns pontos:

1. As universidades devem consolidar políticas internas de propriedade intelectual e patentes;

2. Dispor de sistemas de informação;

3. Gestão adequada de papéis e contratos;

4. Dispor de uma equipe multidisciplinar capacitada para gestão de negociações;

5. Qualificar recursos humanos para gerenciamento e busca de incentivos em órgãos de fomento. (ÁVILA DE MATOS e KOVALESKI, 2001, p.11).

Figura 1 - Entorno para Negociação Eficaz ${ }^{*}$

Erro!

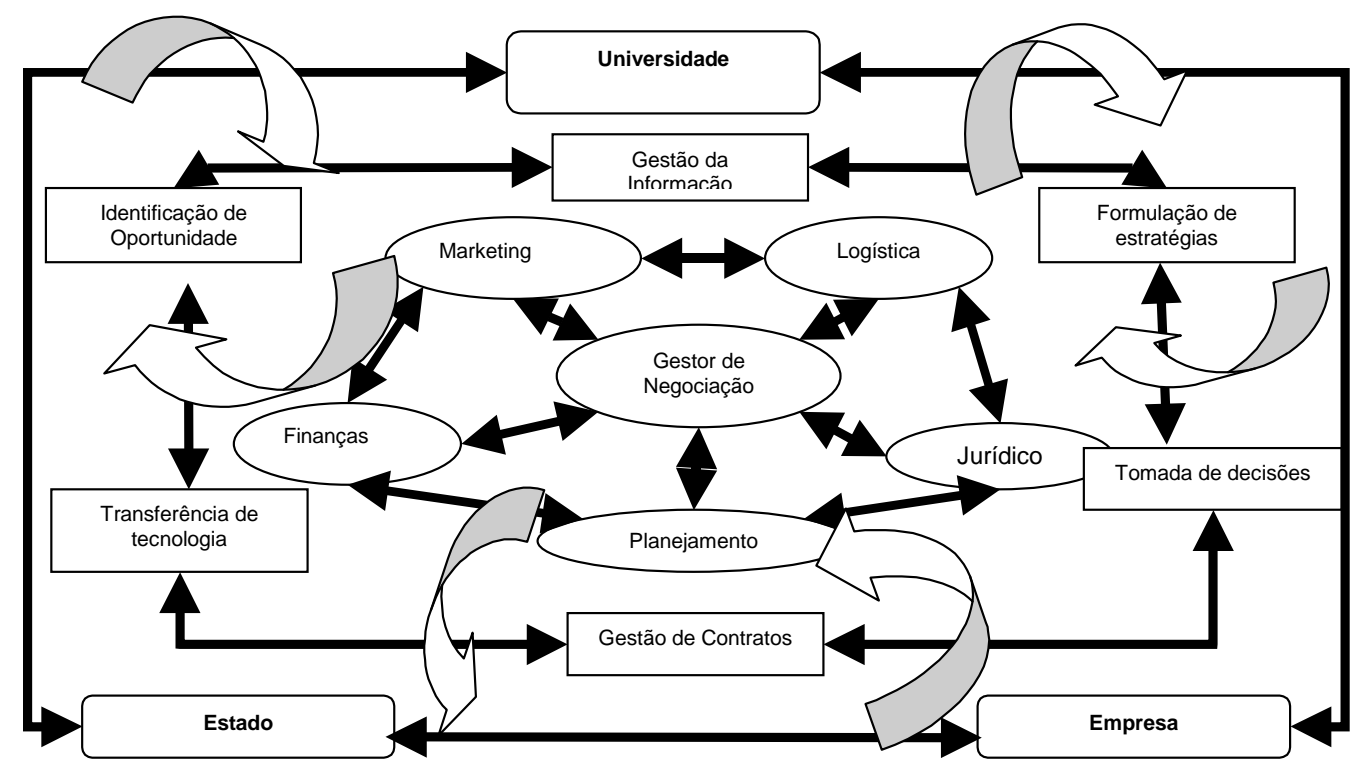


Em abordagem anterior, defendemos a concepção de que o processo de negociação contempla um repertório de comportamentos que exige conexão entre conhecimentos multidisciplinares.

A negociação entre universidade-empresa -governo envolve diversos aspectos em que a resolução de problemas e a tomada de decisão constituem objetos de estudo e investigação, para as quais é necessário recorrer ao uso de várias áreas.

O entorno é um sistema integrado por partes relacionadas entre si, que trabalham em harmonia umas com as outras, para alcançarem objetivos internos e externos do sistema.

É um sistema "aberto" (não-isolado) no plano da troca de energia (informação) isto é, depende das interações com seu meio; mas ao mesmo tempo, é operacionalmente "fechado" no plano relacional, ou seja, tem uma certa autonomia para "administrar" suas interações com o meio.

As áreas que integram o sistema devem ser administradas de tal forma que providenciem as informações necessárias para assimilação e ajustes de comportamento.

O entorno está organizado em três sistemas:

a) Sistema Ambiental: constituído pela relação tríplice universidade-empresa-governo é o espaço econômico, político e social que influenciam as variáveis de objetos de negociação para transferência de tecnologia.

b) Sistema Competitivo: marcado pelo processo informativo-decisional e distribuição de recursos.

c) sistema Interno: composto por subsistemas - marketing, finanças, jurídico, planejamento, logística com função de apoio e regulação.

No centro, encontra-se o gestor da negociação o elo entre as entradas e saídas de informação, emprega as informações e materiais para executar as tarefas; é um censor para medir as variações internas e externas da negociação. Sua função é facilitar a eficácia das operações dos subsistemas funcionais.

No sistema interno, o fluxo de informação circula nos subsistemas e fortalecem a gestão da negociação.

Formam-se interações trilaterais entre as áreas de: marketing, finanças e planejamento; bilaterais entre: marketing e planejamento; planejamento e logística; planejamento e finanças; finanças e jurídico; logística e planejamento e destes com o sistema interno.

Os subsistemas marketing, finanças e planejamento são censores para estabelecer as variações internas e externas. A área de marketing avalia a demanda e a importância da inovação ou objeto de negociação, finanças avalia, apreça valores, prevê a relação custo-benefício e o 
planejamento antevê o caminho para adequação dos recursos e estratégias necessárias para o bom desenvolvimento da negociação.

Os subsistemas jurídicos e planejamento compõem o subsistema para tomada de decisões, recebem informações e emitem mensagens de planejamento para ajustes de concessões e acordos.

Logística e planejamento atuam também como controle, organizam e acompanham as atividades de negociação.

O sistema competitivo está interligado ao ambiental e como caracterizamos a proposta de metodologia principiada pela identificação de oportunidade a partir das relações com o mercado, os subsistemas de marketing e finanças desencadearão o processo de coleta de demandas contemplando as informações iniciais para todo o planejamento e execução do processo de negociação para a transferência de tecnologia.

O entorno é genérico e podem se formar quantos subsistemas forem necessários de acordo com as tipologias de objetos de negociação.

O gerenciamento eficaz da negociação depende do processo de planejamento que deve adequar as ações vislumbrando a eficiência das partes para alcançar a eficácia de todo o sistema.

\section{2 - Etapas metodológicas para negociação da transferência de tecnologia entre universidade- empresa}

O entendimento de que toda a negociação é um processo que comporta três momentos distintos, permitiu-nos elaborar as etapas, subdividindo-as em pré-negociação, negociação e pósnegociação.

A primeira etapa - a pré-negociação — vem alicerçada pelas fases de identificação de oportunidades; análise do ramo empresarial; estabelecimento de contatos e coleta de propostas.

Consideramos que o sucesso de uma negociação inicia com uma boa preparação e com um bom banco de dados, que além de manter um histórico de negociações anteriores sobre os aspectos técnico, econômico, financeiro e jurídico, deve conter igualmente informações sobre a organização com a qual se está negociando - estrutura de decisão; decisores; limite de autoridade; portas ou passagens; pessoas que encontraremos pelo caminho para chegar aos decisores. Tendo em vista estes pontos, caracterizamos a primeira etapa como uma área comportamental subsidiada pela linguagem interpessoal que valoriza informações sobre crenças, estilos comportamentais, valores, condições físicas dos negociadores e cultura organizacional. Ela também prevê o desenvolvimento de um sistema de comunicação interna e de acesso aos dados de forma rápida e eficiente.

$\mathrm{Na}$ etapa de negociação, propriamente dita, a ênfase se dá aos aspectos técnicos de negociação que buscam as melhores táticas e estratégias de condução do processo. Compõem-na as 
fases referentes ao plano de negócios e estratégias de negociação; caracterização das relações contratuais; fechamento da negociação.

As equipes de apoio têm um papel extremamente necessário e contribuem para que os negociadores tenham mais informações, análises precisas e sugestões sobre os desdobramentos possíveis. Denominamos esta área de tecnologia, porque ela resulta da somatória de diversos conhecimentos específicos, de perfis dos negociadores e por se tratar, também, da fase de formalização. A linguagem técnica e jurídica permeará esta etapa, sem, contudo não nos esquecermos de que nesse momento o domínio da ontologia conversacional norteará a negociação para o posicionamento ganha-ganha.

A pós-negociação constitui a última etapa da metodologia e engloba as fases de monitoramento do atendimento e sustentação de negócios.

Consideramos que a negociação só se encerra quando o acordo for cumprido e não quando for formalizado; portanto, a implementação favorecerá a relação e a definição do acordo. O controle e a comunicação entre as partes permitirão um verdadeiro desfecho com sucesso. Assim, relacionamos esta etapa à área de controle, avaliação e marketing e para tanto as linguagens e sistemas de qualidade de informação subsidiarão o escopo final desta metodologia.

Outro ponto importante a ser destacado é a orientação da formatação de linguagens distintas para cada área em suas etapas, com isso é possível formar massa crítica de negociadores e cultura de negociação.

\subsection{1 - Identificação, prospecção, avaliação, qualificação e hierarquização das necessidades de inovação}

A dificuldade da identificação do que se poderia chamar de demanda tecnológica pode ser apontada como fato principal do desencontro entre empresa e universidade e/ou institutos de pesquisa.

A palavra identificação tem o mesmo significado de descobrir e está ligada por sua vez à conotação de explorar novas possibilidades, significa ainda evidenciar aquilo que não está aparente, identificar algo que está lá, fazer emergir o que está encoberto.

Uma negociação não acontece se não houver identificação de expectativas de outra parte. É necessário, portanto, para um processo de transferência de tecnologia a identificação de demanda tecnológica que permita evidenciar a situação atual e a situação pretendida, denunciando necessidades e problemas.Para tanto, indicamos dois caminhos: realizar pesquisas de campo explorando o viés comercial e criar um sistema de relações interpessoais com o setor produtivo. 
O primeiro recurso - a pesquisa de campo direcionada às empresas caracterizará somente o porte; a formação e a cultura organizacional das empresas.

... a entrevista direta será pouco fértil. Isto é, uma empresa terá dificuldade em informar as suas carências e necessidades tecnológicas ainda não agraciadas. [...] seguramente, algumas das necessidades apontadas nesse tipo de entrevistas são teóricas desvinculadas de contexto comercial que a empresa se insere. Souza Neto (1994, p. 4).

Tendo em vista o exposto, a análise deve se realizar a partir do contexto comercial, isto é, as transações entre as empresas, o processo de compra e venda, custos e investimentos. Desse modo a pesquisa se estenderá aos clientes da empresa que podem sinalizar quais são as melhorias para o produto ou serviço e evidenciar referenciais de investimentos para a inovação.

Uma empresa competente em um determinado setor será uma boa fonte de informação para as tecnologias que ela pratica ou a que pratica o seu principal concorrente.

Numa outra escala, os fornecedores de matérias primas, equipamentos, softwares e serviços podem apontar e participar das inovações.

Essa etapa metodológica requer que o negociador elabore uma conexão entre o problema e a solução.

Ao identificar a oportunidade de inovação, verifica os reais interesses e necessidades da empresa, sua capacidade tecnológica e delineia as possibilidades múltiplas de efetivação da demanda.

O segundo recurso diz respeito e conduz a habilidades de relacionamento e à criação de uma linguagem interpessoal de fortalecimento das relações entre universidade-empresa, refere-se ao aspecto comportamental. Acontece de forma sutil, aproximando universidade e empresa, desencadeando possibilidades de alianças estratégicas de desenvolvimento para ambos os segmentos.

As informações são levantadas a partir de dados expostos ou observados por: visitas técnicas a empresas por acadêmicos, professores, professor-pesquisador; estágios praticados por acadêmicos e/ou professores pesquisadores; participação de empresários em Conselhos Empresariais dentro das universidades; workshops para discussão de desenvolvimento setorial e para apresentação de tecnologias, materiais e produtos; seminários; reuniões em federações de indústria e associações comerciais e outros...

A habilidade de relacionamento - interpessoal - é entendida como uma metodologia de sinergia vinculada às percepções, atitudes e, sobretudo aos valores dos participantes e conseqüentemente às suas filosofias organizacionais e necessidades de desenvolvimento tecnológico. 
Os dados obtidos geram oportunidades para a efetivação de atividades compartilhadas para solução de problemas e inovação. Permite a prospecção, avaliação e hierarquização das oportunidades diagnosticadas.

\subsection{2 - Análise estrutural do ramo empresarial}

As informações coletadas permitirão comparar os perfis das empresas listadas na prospecção com o perfil do cliente ideal, e a compreensão das áreas de negócios. São informações relacionadas à estrutura do setor industrial e permitem a descrição das relações entre eles.

\subsection{3 - Estabelecimento de contatos e colocação de propostas}

O principal trabalho, nessa fase, é levar informações e posicionar propostas diante das expectativas do cliente, ampliando e utilizando as informações de que dispõe. É marcado pela troca de informações, reconhecimento das características dos negociadores, consolidação de critérios objetivos sobre os quais se possa mais tarde conceder ou exigir concessão.

\subsection{4 - Negociação e desenvolvimento de posição}

A perspectiva é transformar cada proposta em um fechamento iminente de negócio. $\mathrm{O}$ papel fundamental do negociador é ampliar e fortalecer o relacionamento, consolidar pontos fortes e neutralizar perigos, pela cobertura de todos os influenciadores da decisão, criar um clima de interesse e confiança em torno da proposta.

\subsection{5 - Plano de negócios e estratégias de negociação}

Nessa fase desenvolve-se o estudo de viabilidade técnico-econômica, quanto será investido para se obter o retorno desejado; ocorre o alicerçamento de projeto e estabelecimento de metas e cronogramas de desempenho.

O papel do negociador é analisar as vantagens competitivas; o que seria uma transação justa, qual o limite aceitável, quais os riscos.

\subsection{6 - Caracterização das relações contratuais}


Configura-se pelo estudo de contratos com amarras de temporalização, ações legais a serem desempenhadas pelos atores envolvidos; e dinâmicas de proteção intelectual e industrial e ou outro tipo de proteção.

A contratação exige um escopo metodológico de pessoal especializado na área porque a redação de contrato apresenta diferentes graus de formalidade e, portanto requer a participação de um especialista em redação de contratos, familiarizado com a terminologia técnica-legal e da transação negociada.

\subsection{7 - Fechamento da negociação}

É momento para superar problemas de última hora; estabelecer detalhes a respeito da parceria e sua pós-finalização.

A decisão da parceria para a transferência de tecnologia está amadurecida e formaliza -se a assinatura de contrato ou convênio.

\subsection{8 - Monitoramento do atendimento}

Após o processo de fechamento da negociação para contratação de serviços tecnológicos movimentam-se os processos de atendimento ao cliente-empresa envolvendo uma série de atividades dentro da universidade, tanto quanto, na maior parte das vezes dentro da empresa contratante.

O sucesso de futuras negociações dependerá do andamento desses trabalhos, portanto deve ser um compromisso dos negociadores acompanharem e monitorarem o trabalho tanto no "front" interno da universidade quanto diante do cliente.

\subsection{9 - Sustentação e expansão de negócios}

Esta fase faz alusão à organização de relatórios descritivos de ações durante o processo de negociação da prestação de serviço tecnológico. Forma-se um banco de dados com registros de informações pertinentes ao processo, a avaliação do conjunto de operações realizadas durante o desenvolvimento do trabalho contratado e resultados. Compondo, dessa forma, referencial para reestudos e implementações de novas tecnologias ou situações de negociação semelhantes. 
Fluxograma das etapas da Metodologia de Negociação para Transferência de Tecnologia entre UniversidadeEmpresa

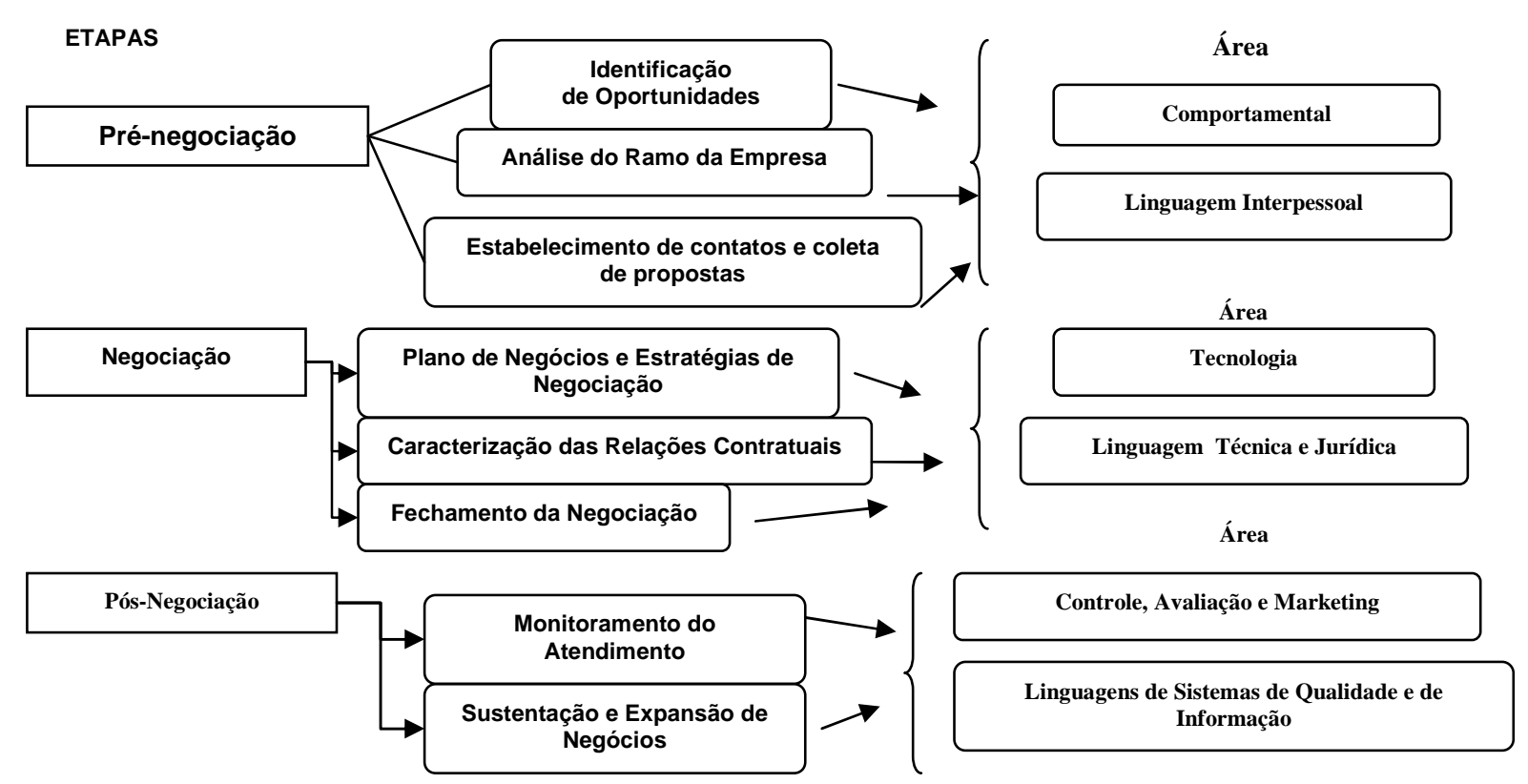

\section{Considerações finais}

Ao delinearmos essa proposta de metodologia para negociação visualizamos uma movimentação contrária ao que vem acontecendo normalmente que é a empresa buscar a parceria da universidade. A universidade pode interferir no desenvolvimento tecnológico das empresas de sua região e buscar parcerias estratégicas, para isso concorrem o processo de identificação de oportunidades de transferência de tecnologia, uma forte estrutura para desenvolvimento de tecnologia e, por conseguinte sua negociação e transferência.

Ao expormos didaticamente a metodologia de negociação distribuímo-la, assim, em três fases.

A primeira fase a pré-negociação — caracteriza o planejamento, que antecede à mesa de negociação, propriamente dita, e refere-se à construção de um caminho de conhecimento mútuo com vistas a criar elos e um relacionamento profícuo. Caracterizada como uma área comportamental ancorada pela linguagem interpessoal, pressupõem negociadores com grande 
potencial de comunicação, capazes de criar um canal de comunicação interno e externo, desenvolvendo comportamentos que gerem confiança.

A identificação de oportunidades desencadeia a análise do porte tecnológico das empresas e possibilidades de inovação tecnológica. Desse modo, o negociador formula o estabelecimento de contatos e coleta de propostas empregando habilidades de argumentação e persuasão.

A segunda etapa denominada de negociação - pode ser considerada como uma etapa mais sistematizada, na qual o objeto de negociação está definido. Envolve o planejamento, execução e controle da negociação numa seqüência lógica e pré-determinada, por isso caracterizada como área tecnológica. Requer a mobilização de estratégias e táticas de negociação, bem como o conhecimento do objeto em negociação (características do produto, serviço ou idéia): dados relativos a mercado, vantagens competitivas, legislação, ações governamentais, aspectos financeiros.

A linguagem é predominantemente técnica, pois requer formulação de estratégias, tomada de decisão. A linguagem jurídica permeia a gestão de contratos e convênios.

$\mathrm{Na}$ terceira fase, a pós-negociação, determinada pelas fases de monitoramento do atendimento e sustentação e expansão de negócios está marcada como área de controle, avaliação e marketing porque alicerça a negociação em andamento por mecanismos de registro, de controle e avaliação do processo de negociação, o que permite o desenvolvimento do marketing interno e externo. A adequação da linguagem de sistemas de qualidade consubstancia na universidade a missão, função e política institucional. A linguagem de informação, por sua vez, constitui uma ferramenta expressiva para gestão da informação, gerando dados tanto para controle quanto para divulgação de experiências e base para outros processos semelhantes.

Desse modo, sugerimos que a universidade deve favorecer a gestão da interação Universidade-Empresa estruturando um entorno eficaz para a transferência de tecnologia, aliando a competência acadêmica à capacidade de negociar projetos e contratos.

A proposta de metodologia de negociação entre Universidade-Empresa constitui-se estratégia para definição de projetos alternativos, de forma a se pensar quais as ações que deverão ser tomadas para a minimização de diferenças e percalços pelos quais Universidade-Empresa passam no processo de interação.

Vale ressaltar ainda que cada negociação tem um perfil próprio e a metodologia delineada — de base conceitual e generalista — e se dá basicamente em três etapas que permitem o conhecimento das características de cada parceiro, seus paradigmas, sua política, atuação e valores; o estabelecimento de uma linguagem de negociação adequada a cada etapa do processo. 
A implantação dessa proposta de metodologia de negociação deve ser efetivada em dois momentos: formação de pessoal em técnicas de negociação, gestão de contratos, propriedade intelectual; num segundo momento a adequação de ambiente.

Uma vez que os agentes de negociação entre Universidade e Empresa e Governo entendam a fenomenologia da negociação e vislumbrem-na como meio de alcançar os objetivos organizacionais de cada segmento, deve-se dimensionar o volume de negociações, o provável número de negociadores e de equipes necessárias que considerem parâmetros como liderança, processos, estrutura, qualificação, apoio logístico, banco de dados, sistemas de comunicação e informação.

\section{ABSTRACT}

The search for forms, ways and strategies supported and stimulated by governmental politics that allow the favorable development of a context for the technological innovation, constituted of all the social segments, become narrow the cooperation activities between the Universities and the Companies in way that these partners complement themselves and promote a greater technological qualification and economical development .The success of these partnerships, is ruled under the way of the negotiations, it depends on the interfaces efficient management - since the co-workers alignment of perceptions of the regarding which are the different objectives aimed at, to the relation and stipulizing that each culture imposes, until the management of the projects and activities involved in the transformation of the stipulated objective in tangible results. The existence of a methodological guiding for negotiation among university-company-government contributes for the improvement and magnifying of the relations with partners and facilitates the technology transference of the universities for the companies, constituting important vector for the technological innovation process. Thus, the main objective of this work is to present a proposal of negotiation methodology among university-company-government being considered the necessary qualitative reply to the question: how to lead the negotiation process in the relation universitycompany-government in technology transfer? Therefore, the basic nature of the study in question is characterized as exploration, regarding we search a greater understanding about the problem of the interaction university-company-government and the identification of the negotiation processes.

Key Words: negotiation, innovation, relation u-c-g

\section{Referências}

AVILA DE MATOS, E. A. S.; KOVALESKI, J. L.Transferência de tecnologia e gestão da negociação. In: Simpósio de Gestão da Inovação Tecnológica, XXI, 2000, São Paulo. Anais... São Paulo: USP/PGT, 2000.

Managing Negotiations in the cooperation university-industry: perspectives for technology transfer and regional development. In: INTERNATIONAL CONFERENCE ON TECNOLOGY POLICY AND INNOVATION, $4^{\text {th }}, 2000$, Curitiba. Anais... Curitiba: PUC, 2000.

Gestão da negociação no processo de transferência de tecnologia na relação universidade-empresa. In: SEMINÁRIO LATINO-IBEROAMERICANO DE GESTIÓN TECNOLÓGICA, INNOVACIÓN TECNOLÓGICA EN LA ECONOMÍA DEL CONOCIMIENTO, 9., 2001, Costa Rica. Anais... Costa Rica: ITCR/ALTEC, 2001.

ACUFF, F. L. How to negotiate anything with anywhere around the world. New York: American Management Association, 1993. 
CARVALHO, H. G. Atividades, modelos e desafios na cooperação universidade/empresa. In: CONCURSO DE MONOGRAFIA SOBRE A RELAÇÃO UNIVERSIDADE/EMPRESA, 2., 2001, Curitiba. Anais... Curitiba: IPARDES; IEL-PR, 2001.

COHEN, H. Você pode negociar qualquer coisa. 8. ed. Rio de Janeiro: Record, 1980.

FRACASSO, E. M.; BALBINOT, Z. A propriedade intelectual na interação universidade-empresa: o caso da UFRGS. In: SIMPÓSIO DA INOVAÇÃO TECNOLÓGICA, 19., 1996 São Paulo. Anais... São Paulo, 1996.

JUNQUEIRA, L. A. C. Negociação: tecnologia e comportamento. Rio de Janeiro: COP, 1998.

KWASNICKA, E. L. Introdução à administração. 5. ed. São Paulo: Atlas, 1995.

MATOS, F. G. Negociação gerencial: aprendendo a negociar. Rio de Janeiro: José Olympio, 1985/1989.

NASCIMENTO, M. E. M. Interação universidade empresa na sociedade de informação. Humanidades, Brasília, n. 45, p. 56-61, 1999.

POLLAN, S. M.; LEVINE, M. The total negotiator. New York: Avon Books, 1994.

Cooperação universidade-empresa: um desafio gerencial complexo. Revista de Administração da USP RAUSP, São Paulo, v. 34, n. 4, p. 5-12, out./dez. 1999.

REIS, D. R. Contributos para a melhoria da eficiência e eficácia nas relações de cooperação entre universidades e pequenas e médias empresas industriais brasileiras. 2000. Tese (Doutorado) - Universidade de Aveiro, Aveiro, 2000 .

SÁENZ, T. W.; GARCIA CAPOTE, E. Ciência e Gestão Tecnológica. Brasília: CNI/IEL/SENAI, ABIPITI, 2002.

SANTOS, M. E. R.; FRACASSO, E. M. Sabato's triangle and triple helix: expressions of the same concept? In: TRIPLE HELIX INTERNATIONAL CONFERENCE, 3., 2000, Rio de Janeiro. Anais... Rio de Janeiro: Fundação COPPETEC, 2000.

SHELL, Richard G. Negociar é preciso: estratégias de negociação para pessoas de bom senso. São Paulo: Negócio, 2001.

SOUZA NETO, J. A.; CERANTOLA, W.; GARCIA, C. L. O contrato de tecnologia instituto/empresa. (mimeo). Manaus, 1994. 